\title{
MEK inhibitor, PD98059, promotes breast cancer cell migration by inducing $\beta$-catenin nuclear accumulation
}

\author{
YING ZHAO*, CHAO-CHAO GE* , JUN WANG, XIAO-XIAO WU, XIAO-MIN LI, WEI LI, SHA-SHA WANG, \\ TONG LIU, JIU-ZHOU HOU, HUA SUN, DONG FANG and SONG-QIANG XIE
}

Institute of Chemical Biology, College of Pharmacy, Henan University, Kaifeng, Henan 475004, P.R. China

Received January 14, 2017; Accepted July 28, 2017

DOI: 10.3892/or.2017.5955

\begin{abstract}
Abnormal activation of the RAF/MEK/ERK signaling pathway has been observed in breast cancer. Thus, a number of MEK inhibitors have been designed as one treatment option for breast cancer. Although some studies have found that these MEK inhibitors inhibit the growth of a variety of human cancer cells, some trials have shown that the use of MEK inhibitors as a treatment for breast cancer does not adequately improve survival for unknown reasons. In the present study, MEK inhibitor PD98059 was used to evaluate its anticancer effects on human breast cancer MCF-7 and MDA-MB-231 cells and to explore the possible mechanism of action. Our results revealed that MEK inhibitor PD98059 exhibited antiproliferative effects in a dose- and time-dependent manner in MCF-7 and MDA-MB-231 breast cancer cells. Conversely, incubation of MCF-7 and MDA-MB-231 cells with PD98059 promoted their migration. Further investigation disclosed that the enhanced ability of migration promoted by PD98059 was dependent on $\beta$-catenin nuclear translocation in the MCF-7 and MDA-MB-231 cells. Subsequent experiments documented that activation of EGFR signaling induced by PD98059 increased the amount of $\beta$-catenin in the nucleus. Taken together, our findings may elucidate a possible mechanism explaining the ineffectiveness of MEK inhibitors in breast cancer treatment and improve our understanding of the role of MEK in cancer.
\end{abstract}

\section{Introduction}

Breast cancer is one of the leading causes of cancer-related deaths in women (1). Despite the great advance in the treatment

Correspondence to: Dr Dong Fang or Dr Song-Qiang Xie, Institute of Chemical Biology, College of Pharmacy, Henan University, Kaifeng, Henan 475004, P.R. China

E-mail: emailfangdong@163.com

E-mail: xiesq@henu.edu.cn

${ }^{*}$ Contributed equally

Key words: MEK, breast cancer, migration, $\beta$-catenin, nuclear accumulation of breast cancer, the prognosis of these patients still remains poor to date $(2,3)$. Abnormal activation of the RAF/MEK/ ERK signaling pathway has been observed in breast cancer and was proposed as a candidate for cancer therapy $(4,5)$. Thus, a number of MEK inhibitors have been designed to test their antiproliferative activity against breast cancer cells $(6,7)$. Although some studies have found that these MEK inhibitors inhibit the growth of a variety of human cancer cells, some trials have shown that the use of MEK inhibitors as a treatment for breast cancer does not adequately improve survival for unknown reasons (8-10). Therefore, understanding the reasons for the poor outcome in such treatments implies a better knowledge of the function of the MEK pathway.

Previous studies have suggested that the treatment of breast cancer cells with MEK inhibitors produced an increase in the phosphorylation of the epidermal growth factor receptor (EGFR) through a negative feedback loop $(11,12)$. Activated EGFR phosphorylates the Y593 residue of the protein known as family with sequence similarity 129, member B (FAM129B), resulting in an increased PKM2-dependent $\beta$-catenin transactivation and tumor cell invasion (13). $\beta$-catenin is an important intermediate in several signal transduction pathways including the Wnt pathway (14-16). In the canonical Wnt pathway, $\beta$-catenin accumulates and translocates to the nucleus where it acts as a key transcriptional co-activator to activate a series of genes that are associated with cell proliferation and metastasis in cancer. In addition, EGFR signaling also stimulates the phosphorylation of LRP6, increases the active $\beta$-catenin level, and induces its nuclear translocation (17). Recent studies of breast cancer suggested that $\beta$-catenin nuclear accumulation is usually correlated with poor outcome $(18,19)$. Aberrant upregulation of $\beta$-catenin was observed in various mammary carcinoma cell lines which conferred resistance to PI3K inhibitors $(18,20)$. Therefore, we aimed to ascertain whether EGFR-mediated $\beta$-catenin nuclear accumulation acts as an alternative pathway for the poor outcome related to MEK inhibitors in breast cancer.

In the present study, we used in vitro approaches to investigate the effects of the MEK inhibitor PD98059 on MCF-7 and MDA-MB-231 breast cancer cells. Our results revealed that MEK inhibitor PD98059 exhibited antiproliferative effects in a dose- and time-dependent manner in MCF-7 and MDA-MB-231 breast cancer cells. Conversely, incubation of MCF-7 and MDA-MB-231 cells with PD98059 promoted their 
migration. Further investigation disclosed that enhanced ability of migration by PD98059 was dependent on $\beta$-catenin nuclear translocation in MCF-7 and MDA-MB-231 cells. In addition, we also demonstrated that $\beta$-catenin nuclear accumulation depended on the activation of EGFR induced by PD98059 in the MCF-7 and MDA-MB-231 cells. Taken together, our findings may elucidate a possible mechanism explaining the ineffectiveness of MEK inhibitors in breast cancer treatment.

\section{Materials and methods}

Materials. PD98059 was purchased from Cell Signaling Technology (Beverly, MA, USA). XAV-939, gefitinib and 3-(4,5-dimethylthiazol-2-yl)-2,5-diphenyltetrazolium bromide (MTT) were purchased from Sigma (St. Louis, MO, USA). RPMI-1640 medium and fetal bovine serum (FBS) were purchased from Gibco (Grand Island, NY, USA). The sources of primary antibodies used for western blotting: polyclonal rabbit anti-human $\beta$-catenin (sc-7199; 1:500), monoclonal mouse anti-human p-EGFR (sc-81490; 1:200), monoclonal mouse anti-human $\beta$-actin (sc-47778; 1:1,000) and polyclonal rabbit anti-human lamin B1 antibodies (sc-20682; 1:500) were all purchased from Santa Cruz Biotechnology (Santa Cruz, CA, USA). Polyclonal rabbit anti-human phospho-MEK1 (Thr292) antibody (\#51265; 1:1,000) was purchased from Cell Signaling Technology. The horseradish peroxidase-conjugated secondary antibodies including goat anti-rabbit IgG (sc-2054; $1: 1,000)$ and goat anti-mouse IgG (sc-2973; 1:1,000) were also purchased from Santa Cruz Biotechnology. All other chemicals used in the present study were commercial products of reagent grade.

Cell lines. Cell lines, derived from human breast cancer (MCF-7 and MDA-MB-231) were used in the present study. All of the cell lines were purchased from the Cell Bank of the Chinese Academy of Science (Shanghai, China). These cells were maintained in RPMI-1640 medium containing 10\% FBS, $100 \mathrm{U} / \mathrm{ml}$ penicillin, and $100 \mu \mathrm{g} / \mathrm{ml}$ streptomycin, at $37^{\circ} \mathrm{C}$ in a humidified incubator containing $5 \% \mathrm{CO}_{2}$.

MTT assay. Cells were seeded in 96-well plates at an initial density of $4 \times 10^{3}$ cells/well in $90 \mu \mathrm{l}$ of medium and allowed to grow overnight. After cells grew to $30 \%$ of the bottom of cell culture plates, various concentrations of PD980589 (1, 5, 10,20 and $50 \mu \mathrm{M}$ ) were added to the cells and incubation was carried out for $24 \mathrm{~h}$. Then, $50 \mu \mathrm{l}$ of MTT $(1 \mathrm{mg} / \mathrm{ml})$ was added to each well for $4 \mathrm{~h}$ of incubation at $37^{\circ} \mathrm{C}$ and $100 \mu \mathrm{l}$ dimethyl sulfoxide (DMSO) was added to solubilize the crystal products at room temperature for $10 \mathrm{~min}$ subsequently. The optical density (OD) was measured at a wavelength of $490 \mathrm{~nm}$ with a microplate reader (BioTek, Winooski, VT, USA). Growth inhibition ratio was calculated as follows: Growth inhibition ratio $(\%)=\left(\mathrm{OD}_{\text {control }}-\mathrm{OD}_{\text {drug }}\right) / \mathrm{OD}_{\text {control }} \times 100$. The experiments were repeated at least three times.

Wound scratch assay. The wound scratch assay was performed as previously described $(21,22)$. Cells $\left(2 \times 10^{4}\right)$ were seeded in a 24-well plate and cultured overnight prior to serum starvation. After incubation, a linear wound in the cellular monolayer was created by scratching a confluent cell monolayer. The mono- layer of the scratched cells was washed by phosphate-buffered saline (PBS) to remove debris. After incubation for $24 \mathrm{~h}$, the area of migration was photographed under a microscope. The width of the wound was measured and recorded as $t=0$. The cells were then allowed to migrate back into the wounded area. Twenty-four hours later, the width of the open area was measured. Cell migration was expressed as the percentage of the gap $(\mathrm{t}=24 \mathrm{~h})$ relative to the primary width of the open area $(\mathrm{t}=0 \mathrm{~h})$. All experiments were performed in triplicate.

Cell migration assay. The migration assays were performed in a $24-w e l l$ Boyden chamber with an $8-\mu \mathrm{m}$ pore size polycarbonate membrane (Corning, Corning, NY, USA) as previously described (21-23). For the migration assay, $200 \mu \mathrm{l}$ of serumfree medium (containing $1 \times 10^{5}$ cells) was added to the upper compartment of the chamber, while the lower compartment was filled with $600 \mu 1$ of RPMI-1640 supplemented with $10 \% \mathrm{FBS}$. After incubation at $37^{\circ} \mathrm{C}$ for $24 \mathrm{~h}$, the tumor cells remaining inside the upper chamber were removed with cotton swabs. The cells on the lower surface of the membrane were stained with $0.1 \%$ crystal violet after fixation with methanol, and then counted under a light microscope.

Western blotting. The total proteins were isolated from cancer cell lines using RIPA lysis buffer. The nuclear proteins were isolated from the cancer cell lines using Nuclear and Cytoplasmic Protein Extraction kit (Beyotime, Shanghai, China) following the manufacturer's instructions. The protein concentration was determined using a BCA assay kit (Pierce, Rockford, IL, USA). Samples were denatured in 5X SDS sample buffer at $95^{\circ} \mathrm{C}$ for $5 \mathrm{~min}$. Equal amounts of total proteins were separated using $10 \%$ SDS-PAGE, and then transferred onto polyvinylidene difluoride (PVDF) membranes. The membranes were then blocked with 5\% dried skimmed milk in Tris-buffered saline with Tween-20 (TBST) at room temperature for $1 \mathrm{~h}$. After blocking, the membranes were incubated with corresponding primary antibodies overnight at $4^{\circ} \mathrm{C}$. After being washed three times with TBST, the membranes were incubated with the appropriate HRP-conjugated secondary antibody, and then washed three times with TBST. Proteins were detected using the Enhanced Chemiluminescence (ECL) Plus reagents (Beyotime).

Statistical analysis. Statistical analyses were performed using GraphPad Prism 5 for Windows (GraphPad Software, Inc., La Jolla, CA, USA). All data are expressed as mean \pm SEM. A two-tailed unpaired t-test was used for the comparison of the mean values between two groups. One-way analysis of variance (ANOVA) followed by Dunnett's multiple comparison test or two-way ANOVA followed by Bonferroni post hoc test was used for multiple comparison. Differences with $\mathrm{P}<0.05$ were considered statistically significant.

\section{Results}

Antiproliferative effects of PD98059 on MCF-7 and MDA-MB-231 cells. MCF-7 cells are estrogen receptor-positive breast cancer cells and MDA-MB-231 is a triple-negative breast cancer. Therefore, we selected these two cell lines with different genetic backgrounds for our studies. PD98059, one 

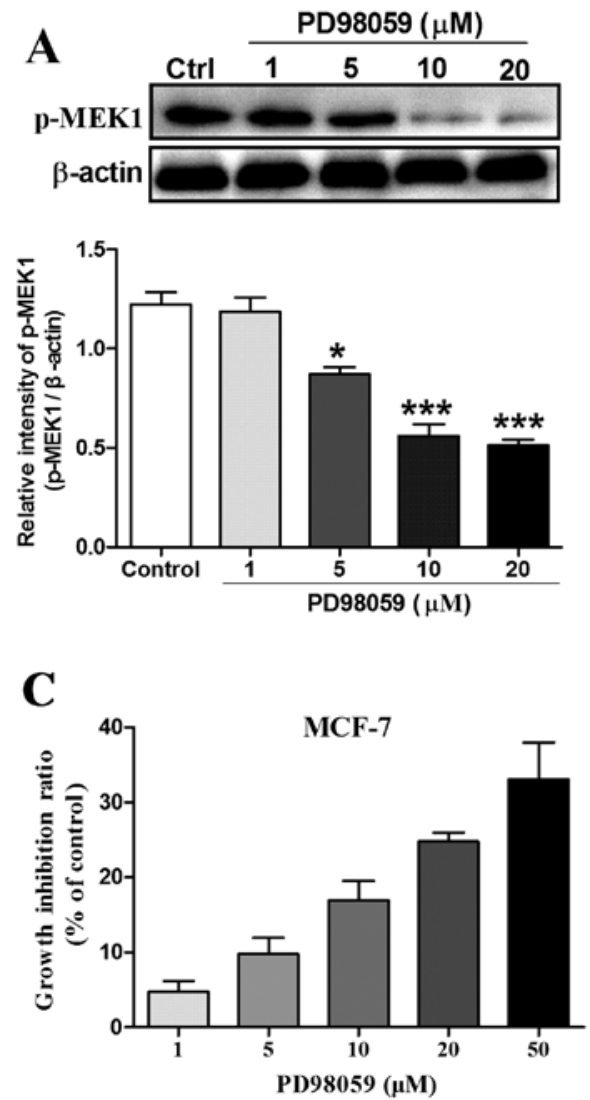
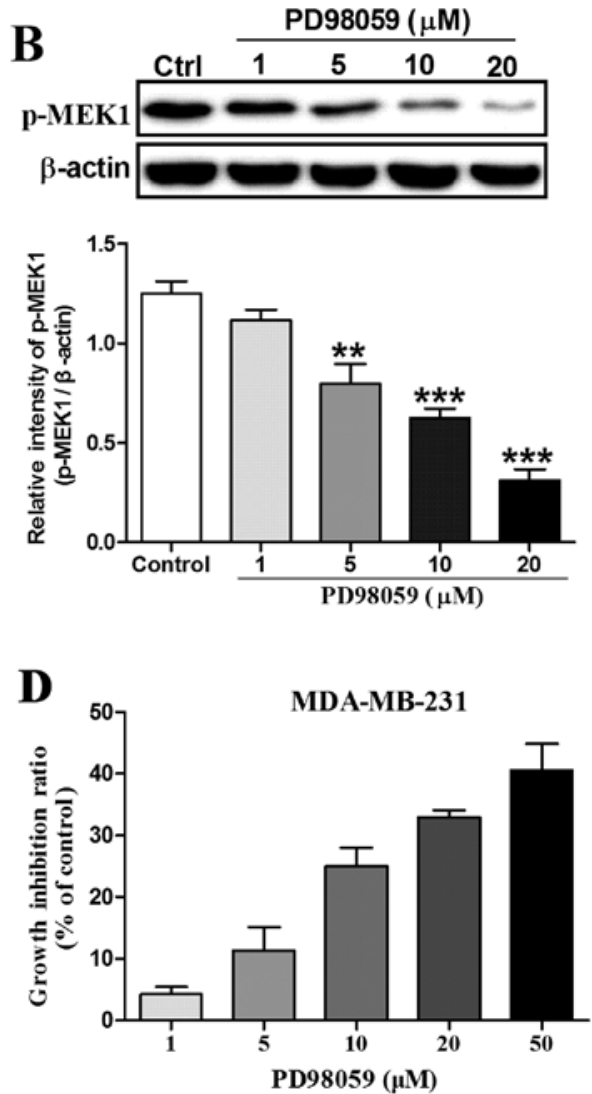

Figure 1. Inhibition of MEK activation with PD98059 attenuates cell growth in a dose-dependent manner. (A) Western blot analysis showed that pretreatment of MCF-7 cells with PD98059 inhibited MEK1 phosphorylation. (B) Western blot analysis showed that pretreatment of MDA-MB-231 cells with PD98059 inhibited MEK1 phosphorylation. (C) MTT assay showed that PD98059 inhibited MCF-7 cell growth in a dose-dependent manner. (D) MTT assay showed that PD98059 inhibited MDA-MB-231 cell growth in a dose-dependent manner. All of the results were repeated in three independent experiments; ${ }^{*}<0.05$; ${ }^{* * *} \mathrm{P}<0.01,{ }^{* * *} \mathrm{P}<0.001$ compared to the control group; one-way ANOVA.
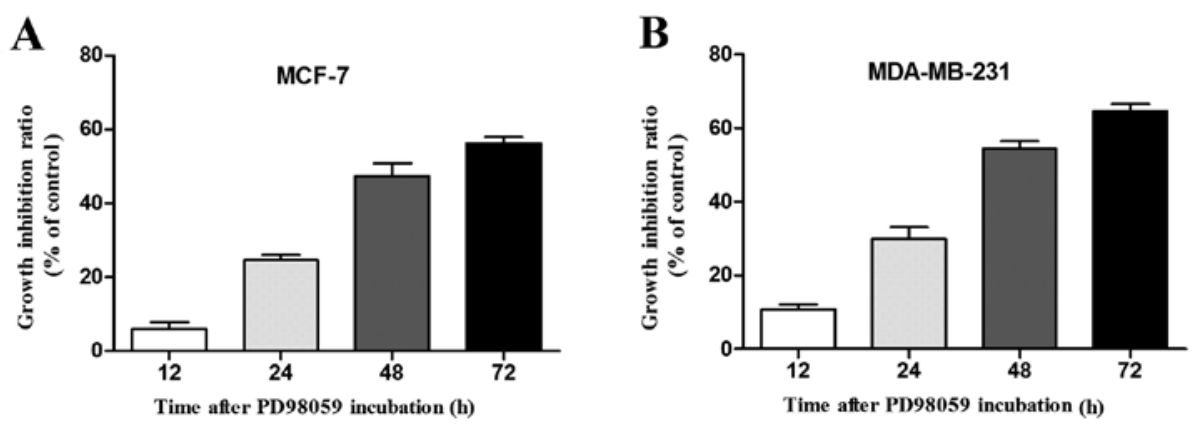

Figure 2. PD98059 inhibits breast cancer cell growth in a time-dependent manner. (A) MTT assay showed that PD98059 (20 $\mu$ M) inhibited MCF-7 cell growth in a time-dependent manner. (B) MTT assay showed that PD98059 $(20 \mu \mathrm{M})$ inhibited MDA-MB-231 cell growth in a time-dependent manner. All of the results were repeated in three independent experiments.

of the first selective MEK inhibitors, is a potent and selective inhibitor of MEK with anticancer activity in vitro. To determine the antiproliferative effects of PD98059 on breast cancer cells, we first treated MCF-7 and MDA-MB-231 breast cancer cells with 1, 5, 10 and $20 \mu \mathrm{M}$ PD98059 for $24 \mathrm{~h}$. As shown in Fig. 1A and B, after incubation of the MCF-7 and MDA-MB-231 cells with 1, 5, 10 and $20 \mu \mathrm{M}$ PD98059 for $24 \mathrm{~h}$, the expression of phosphorylated MEK1 which is an indicator of MEK1 activation was markedly decreased from 5 to $20 \mu \mathrm{M}$ compared with the control group. Then, we observed that PD98059 inhibited MCF-7 and MDA-MB-231 cell proliferation in a dose-dependent manner using MTT assay (Fig. 1C and D). For example, the cell growth inhibition ratio was increased from $4.7 \%$ at the dose of $1 \mu \mathrm{M}$ to $33.1 \%$ at the dose of $50 \mu \mathrm{M}$ in MCF-7 breast cancer cells. Similarly, the cell growth inhibition ratio was increased from $4.2 \%$ at the dose of $1 \mu \mathrm{M}$ to $40.5 \%$ at the dose of $50 \mu \mathrm{M}$ in the MDA-MB-231 breast cancer cells. In addition, we further evaluated whether PD98059 exerts antiproliferative activity in a time-dependent manner in the breast cancer cells. As our results showed, the growth inhibition ratio in the MCF-7 cells incubated with $20 \mu \mathrm{M}$ PD98059 was markedly increased from $6.1 \%$ at $12 \mathrm{~h}$ to $56.2 \%$ at $72 \mathrm{~h}$ (Fig. 2A). Accordingly, the growth inhibition ratio in the MDA-MB-231 cells incubated 
A

A DMSO

\section{PD98059}
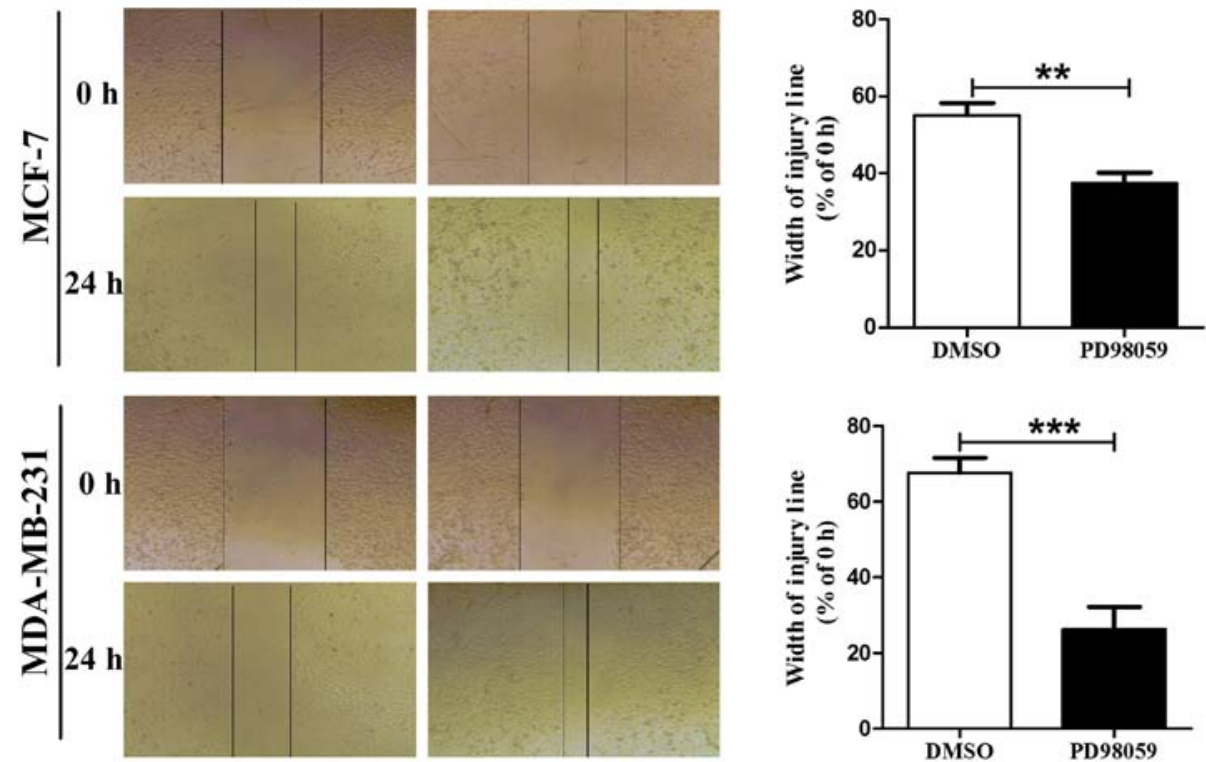

B
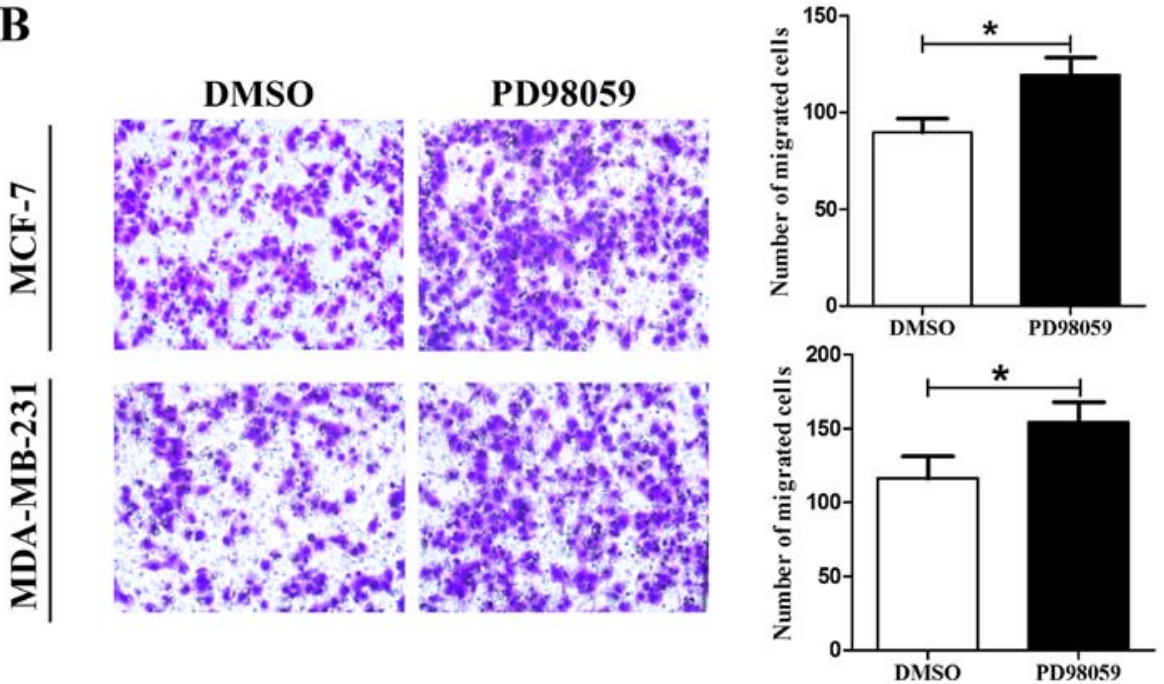

Figure 3. PD98059 promotes breast cancer cell migration. (A) Wound healing assays indicated that PD98059 (20 $\mu \mathrm{M}$ for $24 \mathrm{~h})$ promoted MCF-7 and MDA-MB231 cell migration. (B) Transwell assay without Matrigel demonstrated that PD98059 (20 $\mu \mathrm{M}$ for $24 \mathrm{~h}$ ) promoted MCF-7 and MDA-MB-231 cell migration. Results are presented as mean \pm SEM $(n=3) ;{ }^{*} \mathrm{P}<0.05$ compared to the control group; one-way ANOVA.

with $20 \mu \mathrm{M}$ PD98059 was also increased from $10.7 \%$ at $12 \mathrm{~h}$ to $64.6 \%$ at $72 \mathrm{~h}$ (Fig. 2B).

PD98059 promotes MCF-7 and MDA-MB-231 cell migration. Given that PD98059 not only influences tumor cell proliferation but also cell motility in several types of cancer cells, we investigated whether PD98059 regulates MCF-7 and MDA-MB-231 cell migration, which is one of the most vital features associated with malignant cell behavior. First, we examined the role of PD98059 in MCF-7 and MDA-MB-231 cell migration using a wound scratch assay. Since $20 \mu \mathrm{M}$ is a commonly used dosage for inhibiting MEK activity $(24,25)$, we selected this concentration for our subsequent experiments. As shown in Fig. 3A, the cells incubated with $20 \mu \mathrm{M}$ PD98059 for $24 \mathrm{~h}$ displayed a higher ability of migration compared with the cells treated with vehicle (DMSO). To further identify these results, we examined the effects of PD98059 on cell migration using the Boyden chamber Transwell assay without Martrigel. Consistent with the wound scratch assay, MCF-7 and MDA-MB-231 cells treated with PD98059 also displayed an increased ability of migration compared with the control group cells (Fig. 3B). These results indicated that PD98059 promoted cell migration in the MCF-7 and MDA-MB-231 cells.

$\beta$-catenin expression in the MCF-7 and MDA-MB-231 cells is increased after treatment with PD98059. Given that $\beta$-catenin is a key mediator for cell proliferation, migration and differentiation, we aimed to ascertain whether $\beta$-catenin is involved in the regulation of cell proliferation and migration in MCF-7 and MDA-MB-231 cells by PD98059. Therefore, we first examined the total protein expression of $\beta$-catenin using western blot assay. As shown in Fig. 4A, the expression of $\beta$-catenin total protein in the MCF-7 and MDA-MB-231 cells 
A

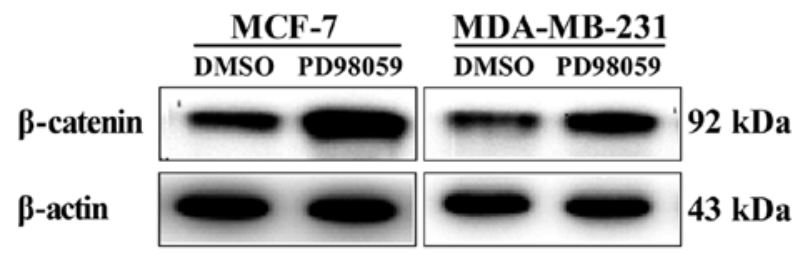

B

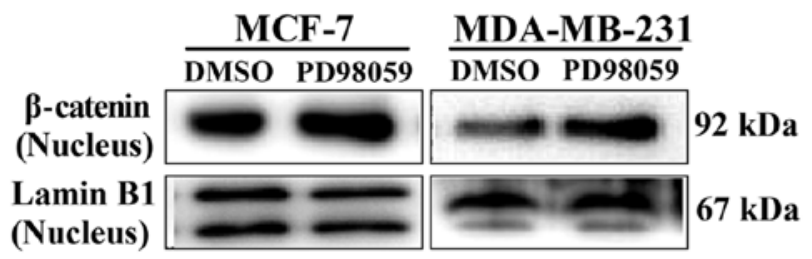

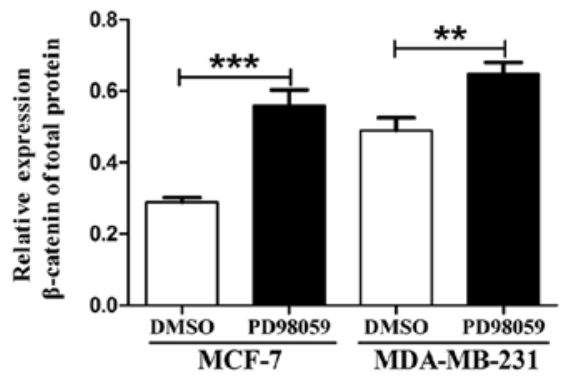

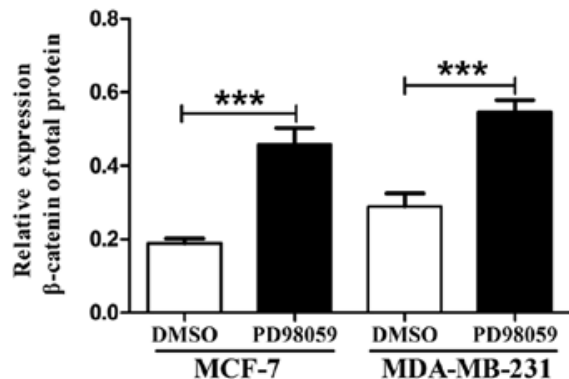

Figure 4. Protein expression of $\beta$-catenin is increased in MCF-7 and MDA-MB-231 cells. (A) $\beta$-catenin total protein and (B) nuclear protein were increased in the MCF-7 and MDA-MB-231 cells treated with PD98059 (20 $\mu \mathrm{M}$ for $24 \mathrm{~h})$. $\beta$-actin and lamin B1 were used as an internal control of total protein and nuclear protein. Results are presented as mean $\pm \operatorname{SEM}(\mathrm{n}=3) ;{ }^{* *} \mathrm{P}<0.01,{ }^{* * * *} \mathrm{P}<0.001$ compared to the control group; a two-tailed unpaired t-test.

A
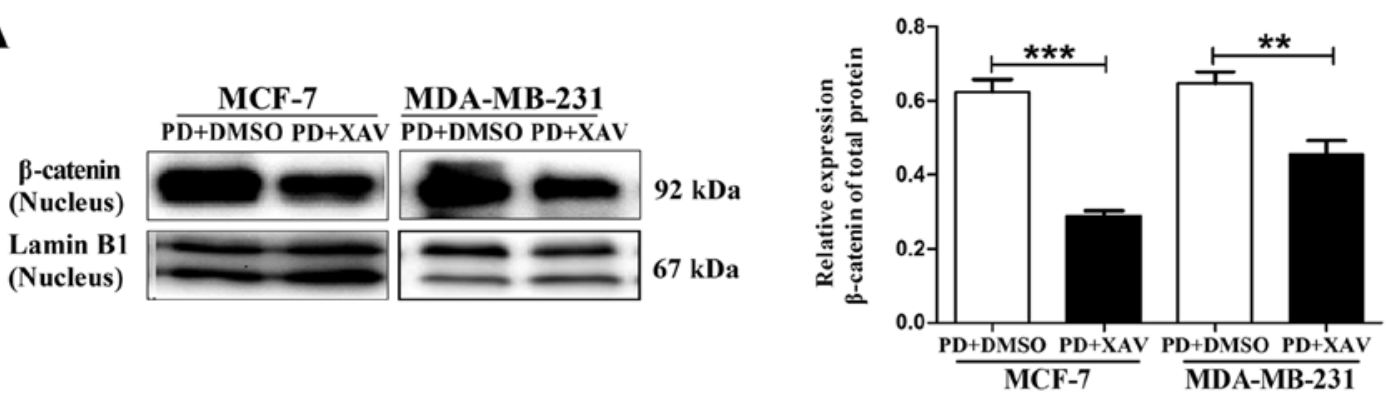

B
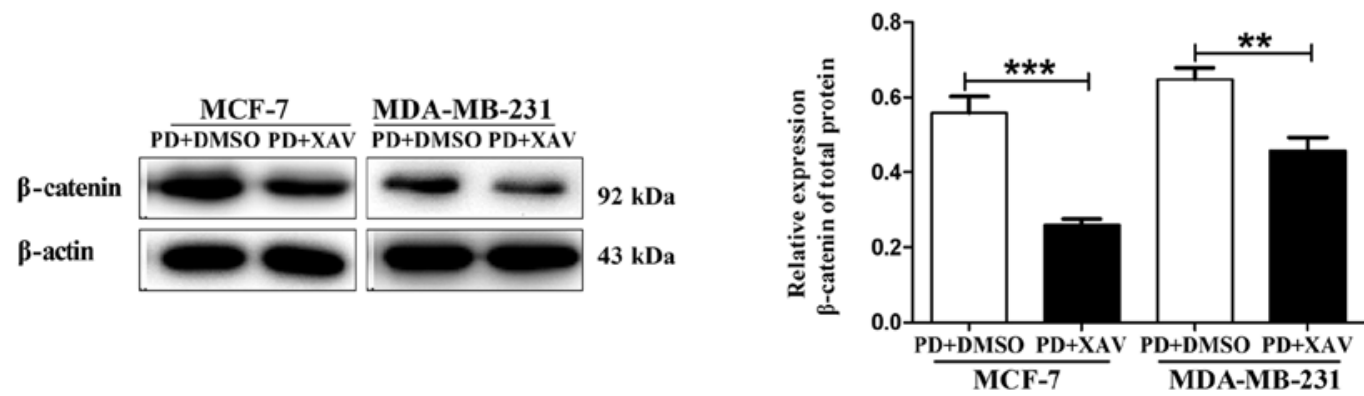

Figure 5. XAV939 reverses PD98059-induced $\beta$-catenin total protein and nuclear protein expression in MCF-7 and MDA-MB-231 cells. (A) Western blot analysis showed that pretreatment of MCF-7 and MDA-MB-231 cells with XAV-939 (5 $\mu$ M for 24 h) reversed PD98059-induced $\beta$-catenin total protein expression. $\beta$-actin was used as an internal control of total protein. (B) Western blot analysis showed pretreatment with XAV-939 (5 $\mu \mathrm{M}$ for $24 \mathrm{~h}$ ) reversed PD98059-induced $\beta$-catenin nuclear protein expression in MCF-7 and MDA-MB-231 cells. Lamin B1 was used as an internal control of nuclear protein. Results are presented as mean $\pm \operatorname{SEM}(n=3) ;{ }^{* *} \mathrm{P}<0.01,{ }^{* * *} \mathrm{P}<0.001$ compared to the control group; a two-tailed unpaired $\mathrm{t}$-test.

was statistically increased at $24 \mathrm{~h}$ after incubation with $20 \mu \mathrm{M}$ PD98059 as compared to $\beta$-catenin expression following incubation with vehicle. Considering that $\beta$-catenin nuclear accumulation often induces efficient metastasis formation by enhancing metastasis-related gene transcription, we analyzed nuclear $\beta$-catenin levels as the most direct way to assess the effects of PD98059 on $\beta$-catenin transcriptional activity. Similarly, we also found that PD98059 significantly increased $\beta$-catenin nuclear accumulation in the MCF-7 and MDA-MB231 cells (Fig. 4B).

Inhibition of $\beta$-catenin nuclear accumulation reverses PD98059-induced MCF-7 and MDA-MB-231 cell migration. In order to determine whether $\beta$-catenin nuclear accumulation contributes to PD98059-mediated enhanced ability of cell migration, the AXIN stabilizer XAV939 was used in the 


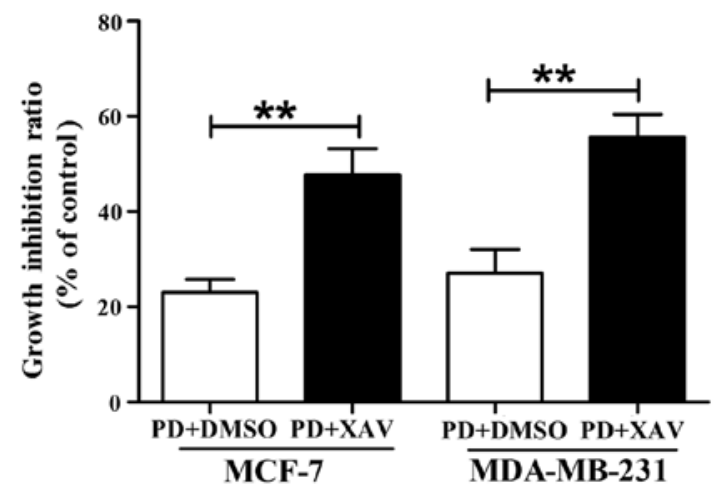

Figure 6. XAV939 $(5 \mu \mathrm{M}$ for $24 \mathrm{~h})$ and PD98059 $(20 \mu \mathrm{M}$ for $24 \mathrm{~h})$ play a cooperative inhibitory role in breast cancer MCF-7 and MDA-MB-231 cell growth These results were repeated in three independent experiments; ${ }^{* * *} \mathrm{P}<0.001$ compared to the control group; a two-tailed unpaired t-test.
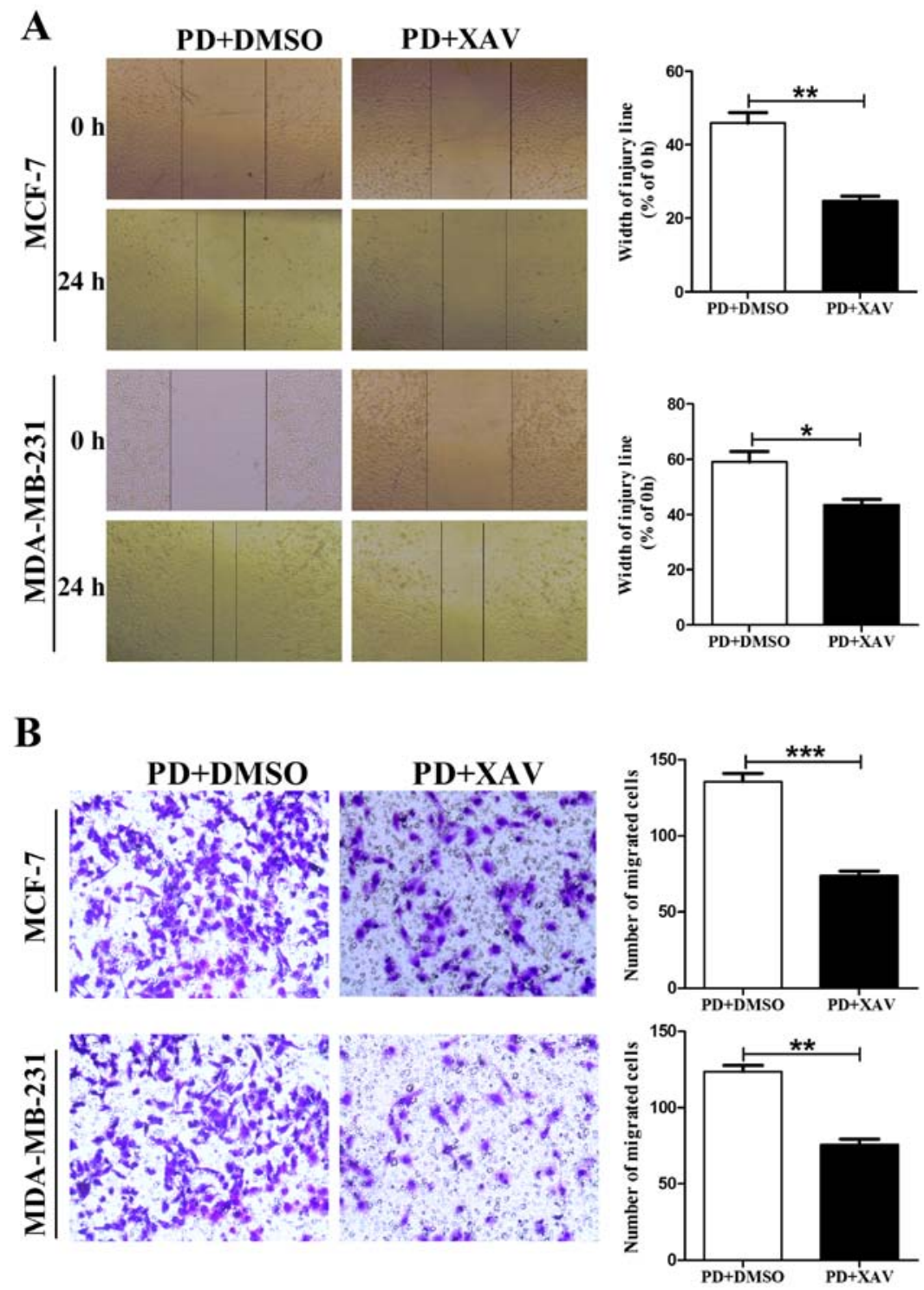

Figure 7. XAV939 reverses PD98059-induced breast cancer cell migration. (A) Wound healing assays indicated that XAV939 (5 $\mu \mathrm{M}$ for $24 \mathrm{~h})$ reversed PD98059-induced MCF-7 and MDA-MB-231 cell migration. (B) Transwell assay without Matrigel demonstrated that XAV939 reversed PD98059-induced MCF-7 and MDA-MB-231 cell migration. Results are presented as mean $\pm \operatorname{SEM}(\mathrm{n}=3) ;{ }^{*} \mathrm{P}<0.05,{ }^{* *} \mathrm{P}<0.01,{ }^{* * * *} \mathrm{P}<0.001$ compared to the control group; a twotailed unpaired t-test.

following study. As a stabilizer of AXIN, XAV939 promotes the degradation of $\beta$-catenin, thus leading to decreased $\beta$-catenin nuclear translocation $(26,27)$. Our results showed that when MCF-7 and MDA-MB-231 cells were pre-treated 
A
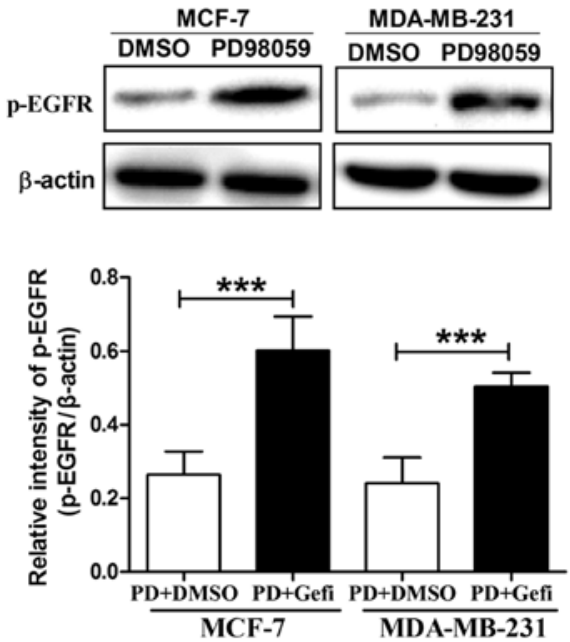

B
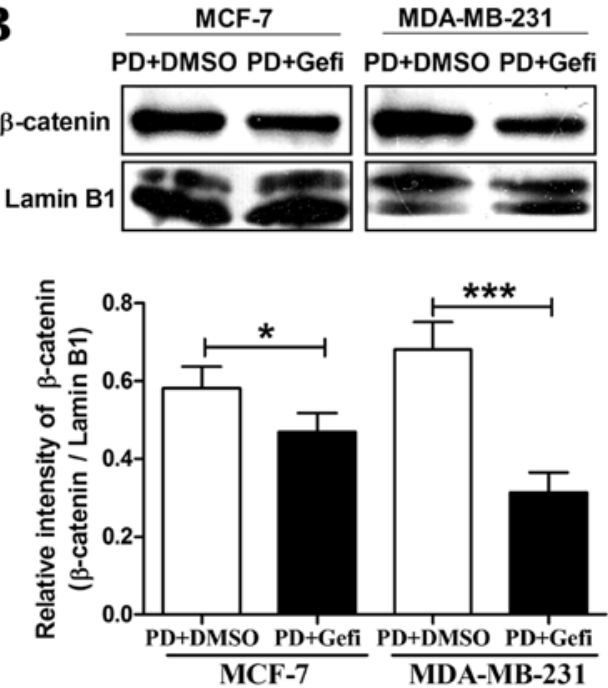

Figure 8. $\beta$-catenin nuclear translocation induced by PD98059 depends on the activation of EGFR in breast cancer cells. (A) Western blot analysis showed that pretreatment of MCF-7 and MDA-MB-231 cells with PD98059 $(20 \mu \mathrm{M}$ for $24 \mathrm{~h})$ promoted $\mathrm{p}$-EGFR protein expression. $\beta$-actin was used as an internal control of total protein. (B) Western blot analysis showed that pretreatment with gefitinib (Gefi) $(20 \mu \mathrm{M}$ for $24 \mathrm{~h})$ reversed PD98059induced $\beta$-catenin nuclear protein expression in MCF-7 and MDA-MB-231 cells. Lamin B1 was used as an internal control of nuclear protein. Results are presented as mean $\pm \operatorname{SEM}(\mathrm{n}=4) ;{ }^{*} \mathrm{P}<0.05,{ }^{* * *} \mathrm{P}<0.001$ compared to the control group; a two-tailed unpaired t-test.

with $5 \mu \mathrm{M}$ XAV-939 for $30 \mathrm{~min}$ followed by co-treatment with PD98059 $(20 \mu \mathrm{M})$ for $24 \mathrm{~h}$, the PD98059-induced increase in $\beta$-catenin nuclear accumulation was markedly blocked by XAV-939 (Fig. 5A). Similarly, PD98059-induced increase in $\beta$-catenin total protein expression was also blocked by XAV-939 in the MCF-7 and MDA-MB-231 cells (Fig. 5B). Then, we examined whether XAV-939 reverses PD98059. mediated changes in cancer cell behaviors. As shown in Fig. 6, XAV-939 did not reverse PD98059-mediated ability to decrease MCF-7 and MDA-MB-231 cell growth, but produced a cooperative inhibitory effect with PD98059 on cell proliferation. Finally, we assessed the effects of XAV939 on cell migration using a wound scratch assay and Boyden chamber Transwell assay without Martrigel. Our results showed that XAV-939 reversed PD98059-induced MCF-7 and MDA-MB231 cell migration (Fig. 7). $\beta$-catenin nuclear accumulation induced by PD98059 depends on the activation of EGFR in breast cancer cells. MEK inhibition is able to induce EGFR activation in breast cancer cells (12), and nuclear translocation of $\beta$-catenin sometimes depends on the activation of $\operatorname{EGFR}(28,29)$. Therefore, we investigated whether activation of EGFR can be induced by MEK inhibitor PD98059 in the MCF-7 and MDA-MB-231 cells. In agreement with previous findings, we also observed an increase in the phosphorylation of EGFR following treatment with $20 \mu \mathrm{M}$ PD98059 for $24 \mathrm{~h}$ in the MCF-7 and MDA-MB-231 cells (Fig. 8A). To elucidate the underlying interaction between EGFR phosphorylation and $\beta$-catenin nuclear accumulation, we then used PD98059 combined with the EGFR inhibitor gefitinib to treat MCF-7 and MDA-MB-231 cells. As shown in Fig. 8B, EGFR kinase inhibitor gefitinib was able to abolish the PD98059-induced $\beta$-catenin nuclear translocation. Hence, we conclude that $\beta$-catenin nuclear accumulation induced by PD98059 depends on the activation of EGFR in breast cancer cells.

\section{Discussion}

The Ras/MEK/ERK pathway plays a central role in cancer cell biology, including proliferation, survival, migration, invasion and angiogenesis $(5,6)$. Therefore, MEK has been proposed as a suitable target for therapeutic intervention in cancer. To our disappointment, numerous studies have found that these inhibitors may showed variable effects on cell growth depending on tumor type $(6,7,30)$. For example, MEK inhibitors showed growth inhibition effects on various types of neuroblastoma, colon cancer and hepatocellular carcinoma cells via inducing apoptosis or G1 phase arrest (30-32), while some breast cancer cell lines were found to be resistant to MEK inhibitors in pre-clinical studies and early clinical trials (10). In the present study, we observed that PD98059 suppressed cell growth in a dose-dependent manner in breast cancer MCF-7 and MDA-MB-231 cells. This is consistent with previous studies by Zhou et al and Ye et al. In their studies, Zhou et al found that the MEK inhibitor suppressed cell growth via induction of apoptosis and G1 phase arrest in the breast cancer MDA-MB-231 and HCC1937 cell lines (33). Ye et al observed that inhibition of MEK/ERK with the pharmacological inhibitor PD98059 resulted in a significant enhancement of growth inhibition in breast cancer MCF-7 cells (34).

In the present study, the expression of $\beta$-catenin was increased in the MCF-7 and MDA-MB-231 cells after treatment with MEK inhibitor PD98059. It is well known that $\beta$-catenin usually acts as a key transcriptional factor and widely participates in promoting cancer cell proliferation and migration $(35,36)$. Why $\beta$-catenin nuclear accumulation induced by PD98059 was associated with decreased cell growth in the present study is unclear. We hypothesize that other proliferation-related signaling pathways were inhibited by the MEK inhibitor. For example, the Raf/MEK/ERK pathway can control cell survival and proliferation by induction of cell cycle regulatory proteins such as BCL-2, CDKs and cyclins. Conversely, MEK inhibition causes reduction in this signaling in cancer cells concomitant with apoptosis $(37,38)$. Although $\beta$-catenin nuclear accumulation occurred after MEK 
inhibition in the MCF-7 and MDA-MB-231 cells, it could not overcome the anti-proliferative signaling pathway which was also induced by the MEK inhibitor. Finally, PD98059 showed antiproliferative effects in the MCF-7 and MDA-MB-231 cells in this case. Of course, further studies are needed to ascertain whether our assumption is correct.

$\beta$-catenin nuclear accumulation often induces efficient metastasis formation by enhancing metastasis-related gene transcription including matrix metalloproteinases (MMPs) (39-41). In the present study, we also demonstrated that $\beta$-catenin nuclear translocation was vital to cell migration in breast cancer MCF-7 and MDA-MB-231 cells, since the MEK inhibitor PD98059 promoted $\beta$-catenin into the nucleus, and inhibition of $\beta$-catenin nuclear accumulation with XAV-939 markedly reversed the cell migration ability induced by PD98059. Subsequent experiments demonstrated that $\beta$-catenin nuclear entry relied on the activation of EGFR in MCF-7 and MDA-MB-231 cells which is in line with previous studies. The epidermal growth factor receptor (EGFR) is a tyrosine kinase receptor that participates in the regulation of cell proliferation and migration. It has been shown that the activation of EGFR signaling stimulates $\beta$-catenin nuclear translocation and contributes to the acquisition of a motile phenotype by upregulating the expression of MMPs $(13,42)$. Although MCF-7 and MDA-MB-231 are cell lines with two totally different genetic backgrounds, EGFR is expressed in these cells $(43,44)$. Therefore, it is not surprising that $\beta$-catenin nuclear translocation induced by PD98059 depends on the activation of EGFR in these breast cancer cell lines.

Contrary to our results in breast cancer cells, previous studies suggest that inhibition of ERK activity in lung cancer activates glycogen synthase kinase $3 \beta$ (GSK3 3 ) potentially leading to $\beta$-catenin degradation, which in turn inhibits cell growth and metastasis $(45,46)$. We hypothesized that these conflicting results may be due to the different tumor types. However, the mechanisms of EGFR overexpression induced by MEK inhibition in breast cancer cells remain unresolved. Further studies are needed to demonstrate this novel pathway and its role in breast cancer progression in vivo. In addition, our results also demonstrated that inhibition of $\beta$-catenin nuclear translocation with XAV-939 inhibited the expression of $\beta$-catenin total protein. This may occur as $\beta$-catenin is retained in the cytoplasm where it is recognized by a destruction complex containing GSK $3 \beta$, casein kinase 1 (CK1), axin and adenomatous polyposis coli (APC), thus leading to ubiquitin proteasome-mediated degradation of $\beta$-catenin $(45,46)$.

Taken together, our results demonstrated that MEK inhibitor PD98059 promoted cell migration in MCF-7 and MDA-MB-231 cells by promoting $\beta$-catenin nuclear translocation. These results may elucidate a possible mechanism explaining the ineffectiveness of MEK inhibitors in breast cancer treatment.

\section{Acknowledgements}

The present study was supported by the National Science Foundation of Henan (162300410039) and the Program for Science and Technology of the Department of Education of Henan Province (16A350013).

\section{References}

1. Torre LA, Bray F, Siegel RL, Ferlay J, Lortet-Tieulent J and Jemal A: Global cancer statistics, 2012. CA Cancer J Clin 65: 87-108, 2015.

2. Castillo LF, Tascón R, Lago Huvelle MR, Novack G, Llorens MC, Dos Santos AF, Shortrede J, Cabanillas AM, Bal de Kier Joffé E, Labriola L, et al: Glypican-3 induces a mesenchymal to epithelial transition in human breast cancer cells. Oncotarget 7: 60133-60154, 2016.

3. Lorusso $\mathrm{G}$ and Rüegg C: New insights into the mechanisms of organ-specific breast cancer metastasis. Semin Cancer Biol 22: 226-233, 2012.

4. Li T, Zhang C, Ding Y, Zhai W, Liu K, Bu F, Tu T, Sun L, Zhu W, Zhou F, et al: Umbilical cord-derived mesenchymal stem cells promote proliferation and migration in MCF-7 and MDA-MB-231 breast cancer cells through activation of the ERK pathway. Oncol Rep 34: 1469-1477, 2015.

5. Neuzillet C, Tijeras-Raballand A, de Mestier L, Cros J, Faivre S and Raymond E: MEK in cancer and cancer therapy. Pharmacol Ther 141: 160-171, 2014.

6. Heigener DF, Gandara DR and Reck M: Targeting of MEK in lung cancer therapeutics. Lancet Respir Med 3: 319-327, 2015.

7. Templeton IE and Musib L: MEK inhibitors beyond monotherapy: Current and future development. Curr Opin Pharmacol 23: 61-67, 2015.

8. Britten CD: PI3K and MEK inhibitor combinations: Examining the evidence in selected tumor types. Cancer Chemother Pharmacol 71: 1395-1409, 2013.

9. Downward J: Targeting RAS signalling pathways in cancer therapy. Nat Rev Cancer 3: 11-22, 2003.

10. Gu Y, Helenius M, Väänänen K, Bulanova D, Saarela J, Sokolenko A, Martens J, Imyanitov E and Kuznetsov S: BRCA1-deficient breast cancer cell lines are resistant to MEK inhibitors and show distinct sensitivities to 6-thioguanine. Sci Rep 6: 28217, 2016.

11. Mirzoeva OK, Das D, Heiser LM, Bhattacharya S, Siwak D, Gendelman R, Bayani N, Wang NJ, Neve RM, Guan Y, et al: Basal subtype and MAPK/ERK kinase (MEK)phosphoinositide 3-kinase feedback signaling determine susceptibility of breast cancer cells to MEK inhibition. Cancer Res 69: 565-572, 2009.

12. Maiello MR, D'Alessio A, Bevilacqua S, Gallo M, Normanno N and De Luca A: EGFR and MEK blockade in triple negative breast cancer cells. J Cell Biochem 116: 2778-2785, 2015.

13. Ji H, Lee JH, Wang Y, Pang Y, Zhang T, Xia Y, Zhong L, Lyu J and Lu Z: EGFR phosphorylates FAM129B to promote Ras activation. Proc Natl Acad Sci USA 113: 644-649, 2016.

14. Jung YS, Jun S, Lee SH, Sharma A and Park JI: Wnt2 complements $\mathrm{Wnt} / \beta$-catenin signaling in colorectal cancer. Oncotarget 6: 37257-37268, 2015.

15. Sano M, Driscoll DR, DeJesus-Monge WE, Quattrochi B, Appleman VA, Ou J, Zhu LJ, Yoshida N, Yamazaki S, Takayama T, et al: Activation of WNT/ $\beta$-catenin signaling enhances pancreatic cancer development and the malignant potential via up-regulation of Cyr61. Neoplasia 18: 785-794, 2016.

16. Wickström M, Dyberg C, Milosevic J, Einvik C, Calero R, Sveinbjörnsson B, Sandén E, Darabi A, Siesjö P, Kool M, et al: Wnt $/ \beta$-catenin pathway regulates MGMT gene expression in cancer and inhibition of Wnt signalling prevents chemoresistance. Nat Commun 6: 8904, 2015.

17. Zhang X, Zhu J, Li Y, Lin T, Siclari VA, Chandra A, Candela EM, Koyama E, Enomoto-Iwamoto M and Qin L: Epidermal growth factor receptor (EGFR) signaling regulates epiphyseal cartilage development through $\beta$-catenin-dependent and -independent pathways. J Biol Chem 288: 32229-32240, 2013.

18. Tzeng HE, Yang L, Chen K, Wang Y, Liu YR, Pan SL, Gaur S, Hu S and Yen Y: The pan-PI3K inhibitor GDC-0941 activates canonical WNT signaling to confer resistance in TNBC cells: Resistance reversal with WNT inhibitor. Oncotarget 6: 11061-11073, 2015.

19. De P, Carlson JH, Wu H, Marcus A, Leyland-Jones B and Dey N: Wnt-beta-catenin pathway signals metastasis-associated tumor cell phenotypes in triple negative breast cancers. Oncotarget 7: 43124-43149, 2016.

20. Timmermans-Sprang EP, Gracanin A and Mol JA: High basal Wnt signaling is further induced by PI $3 \mathrm{~K} / \mathrm{mTor}$ inhibition but sensitive to cSRC inhibition in mammary carcinoma cell lines with HER2/3 overexpression. BMC Cancer 15: 545, 2015. 
21. Chen L, Kang QH, Chen Y, Zhang YH, Li Q, Xie SQ and Wang CJ: Distinct roles of Akt1 in regulating proliferation, migration and invasion in HepG2 and HCT 116 cells. Oncol Rep 31: 737-744, 2014.

22. Zheng XH, Nie X, Liu HY, Fang YM, Zhao Y and Xia LX: TMPyP4 promotes cancer cell migration at low doses, but induces cell death at high doses. Sci Rep 6: 26592, 2016.

23. Liao L, Song M, Li X, Tang L, Zhang T, Zhang L, Pan Y, Chouchane L and Ma X: E3 ubiquitin ligase UBR5 drives the growth and metastasis of triple-negative breast cancer. Cancer Res 77: 2090-2101, 2017.

24. Toulany M, Iida M, Keinath S, Iyi FF, Mueck K, Fehrenbacher B, Mansour WY, Schaller M, Wheeler DL and Rodemann HP: Dual targeting of PI3K and MEK enhances the radiation response of $K-R A S$ mutated non-small cell lung cancer. Oncotarget 7: 43746-43761, 2016.

25. Ren W, Liu Y, Wan S, Fei C, Wang W, Chen Y, Zhang Z, Wang T, Wang J, Zhou L, et al: BMP9 inhibits proliferation and metastasis of HER2-positive SK-BR-3 breast cancer cells through ERK1/2 and PI3K/AKT pathways. PLoS One 9: e96816, 2014.

26. Ma L, Wang X, Jia T, Wei W, Chua MS and So S: Tankyrase inhibitors attenuate $\mathrm{WNT} / \beta$-catenin signaling and inhibit growth of hepatocellular carcinoma cells. Oncotarget 6: 25390-25401, 2015.

27. Huang SM, Mishina YM, Liu S, Cheung A, Stegmeier F, Michaud GA, Charlat O, Wiellette E, Zhang Y, Wiessner S, et al: Tankyrase inhibition stabilizes axin and antagonizes Wnt signalling. Nature 461: 614-620, 2009.

28. Yang W, Xia Y, Ji H, Zheng Y, Liang J, Huang W, Gao X, Aldape $\mathrm{K}$ and $\mathrm{Lu} \mathrm{Z}$ : Nuclear PKM2 regulates $\beta$-catenin transactivation upon EGFR activation. Nature 480: 118-122, 2011.

29. Lee CH, Hung HW, Hung PH and Shieh YS: Epidermal growth factor receptor regulates beta-catenin location, stability, and transcriptional activity in oral cancer. Mol Cancer 9: 64, 2010.

30. Tanaka R, Tomosugi M, Sakai T and Sowa Y: MEK inhibitor suppresses expression of the miR-17-92 cluster with $\mathrm{G}_{1}$ phase arrest in HT-29 human colon cancer cells and MIA PaCa-2 pancreatic cancer cells. Anticancer Res 36: 4537-4543, 2016.

31. Tanaka T, Higashi M, Kimura K, Wakao J, Fumino S, Iehara T, Hosoi H, Sakai T and Tajiri T: MEK inhibitors as a novel therapy for neuroblastoma: Their in vitro effects and predicting their efficacy. J Pediatr Surg 51: 2074-2079, 2016.

32. Wang Y, Nie H, Zhao X, Qin Y and Gong X: Bicyclol induces cell cycle arrest and autophagy in HepG2 human hepatocellular carcinoma cells through the PI3K/AKT and Ras/Raf/MEK/ERK pathways. BMC Cancer 16: 742, 2016.

33. Zhou Y, Hu HY, Meng W, Jiang L, Zhang X, Sha JJ, Lu Z and Yao Y: MEK inhibitor effective against proliferation in breast cancer cell. Tumour Biol 35: 9269-9279, 2014.
34. Ye J, Li A, Liu Q, Wang X and Zhou J: Inhibition of mitogenactivated protein kinase kinase enhances apoptosis induced by arsenic trioxide in human breast cancer MCF-7 cells. Clin Exp Pharmacol Physiol 32: 1042-1048, 2005.

35. Tan Z, Zheng H, Liu X, Zhang W, Zhu J, Wu G, Cao L, Song J, Wu S, Song L, et al: MicroRNA-1229 overexpression promotes cell proliferation and tumorigenicity and activates Wnt/ $\beta$-catenin signaling in breast cancer. Oncotarget 7: 24076-24087, 2016.

36. Jiang Q, He M, Guan S, Ma M, Wu H, Yu Z, Jiang L, Wang Y, Zong X, Jin F, et al: MicroRNA-100 suppresses the migration and invasion of breast cancer cells by targeting FZD-8 and inhibiting Wnt $/ \beta$-catenin signaling pathway. Tumour Biol 37: 5001-5011, 2016

37. McCubrey JA, Steelman LS, Chappell WH, Abrams SL, Wong EW, Chang F, Lehmann B, Terrian DM, Milella M, Tafuri A, et al: Roles of the Raf/MEK/ERK pathway in cell growth, malignant transformation and drug resistance. Biochim Biophys Acta 1773: 1263-1284, 2007.

38. Galante JM, Mortenson MM, Bowles TL, Virudachalam S and Bold RJ: ERK/BCL-2 pathway in the resistance of pancreatic cancer to anoikis. J Surg Res 152: 18-25, 2009.

39. Kobayashi M,Funayama R, OhnumaS, Unno M and Nakayama K: Wnt- $\beta$-catenin signaling regulates ABCC3 (MRP3) transporter expression in colorectal cancer. Cancer Sci 107: 1776-1784, 2016.

40. Lin D, Kuang G, Wan J, Zhang X, Li H, Gong X and Li H: Luteolin suppresses the metastasis of triple-negative breast cancer by reversing epithelial-to-mesenchymal transition via downregulation of $\beta$-catenin expression. Oncol Rep 37: 895-902, 2017.

41. Gu JJ, Rouse C, Xu X, Wang J, Onaitis MW and Pendergast AM: Inactivation of ABL kinases suppresses non-small cell lung cancer metastasis. JCI Insight 1: e89647, 2016.

42. Paul I, Bhattacharya S, Chatterjee A and Ghosh MK: Current understanding on EGFR and Wnt/ $\beta$-catenin signaling in glioma and their possible crosstalk. Genes Cancer 4: 427-446, 2013.

43. Meng X, Hu B, Hossain MM, Chen G, Sun Y and Zhang X: ADAM17-siRNA inhibits MCF-7 breast cancer through EGFRPI3K-AKT activation. Int J Oncol 49: 682-690, 2016.

44. Li RH, Huang WH, Wu JD, Du CW and Zhang GJ: EGFR expression is associated with cytoplasmic staining of CXCR4 and predicts poor prognosis in triple-negative breast carcinomas. Oncol Lett 13: 695-703, 2017.

45. Gao C, Chen G, Romero G, Moschos S, Xu X and Hu J: Induction of Gsk3 $\beta-\beta-\operatorname{TrCP}$ interaction is required for late phase stabilization of $\beta$-catenin in canonical Wnt signaling. J Biol Chem 289 7099-7108, 2014.

46. Gong F, Wang G, Ye J, Li T, Bai H and Wang W: 14-3-3ß regulates the proliferation of glioma cells through the GSK3 $\beta / \beta$-catenin signaling pathway. Oncol Rep 30: 2976-2982, 2013. 